Received 12 April 2019; accepted 4 July 2019.

Available online 1 October 2019

\title{
Impact of ICT on Urban Plannning and Development Management - The case of Water Resources Sector
}

\section{Dr. Heba Nabil abed elhamed ${ }^{1}$}

${ }^{1}$ Lecturer of Environmental Planning Faculty of Urban and Regional PlanningCairo University

Eng_hebanabil @ yahoo.com

\section{Dr. Ahmed Mohammed Marzouk ${ }^{2}$}

2 Lecturer of Regional Planning

Faculty of Urban and Regional Planning-

Cairo University

ahmedmarzouk81@yahoo.com

\section{ABSTRACT}

Water is one of the vital resources of human life. With many changes in climate and population growth, water resources have become inadequate compared to demand. Water management has become a major challenge for both government and the private sector to provide quantities of water with high quality at reasonable cost and rational rate of energy consumption.

Water is a critical component of the urban system, that affects environmental and human health, and nurtures local economic development.

Sustainable development revolves around how to harmonize the indicators of high water demand and good water management to ensure integrated and sustainable development. Through the use of ICT systems, cities seek to achieve a number of additional benefits in the management of the water sector, such as: Accuracy and speed in identifying problems and priorities related to the sector, ensuring that decisions and solutions are taken quickly and accurately, thus achieving continuity and sustainability in water management.

The research aims to achieve the principles of smart cities by measuring some quantitative indicators on the cities of Dakahlia governorate to classify them into three levels that reflect the application of ICT in water resource management and its impact on urban development using various technological capabilities, and then propose some smart water management technologies to achieve the principles of smart cities.

KEYWORDS: Information and Communication Technology - water - management smart cities

\section{INTRODUCTION}

Water is a critical need for human survival. The availability of clean and efficient water is essential for development processes within urban cities, which face many challenges as a result of absolute growth represented by social, economic and environmental challenges. This presents great challenges for urban planners for efficient and sustainable water management due to the stress on water resources resulting from rapid urbanization rates. Demand for clean water supply and adequate sanitation to ensure human dignity (United Nations, 2008).

Rapid urban growth increases competition for scarce water resources among different sectors of development such as industry and agriculture. With this heavy dependence on water resources, any reductions in quantity or quality will have a negative impact on the urban system and in the light of cities' increased production and consumption, Rapid change Sustainable water resources management is a complex issue and 
balancing economic development with water resources sustainability becomes more problematic in light of the current and projected impacts of climate change (eg, sea level rise and water scarcity), It linked to its aging infrastructure weaknesses.

The smart city concept, which is an innovative urban strategy that utilizes high technology to reduce the city's environmental footprint (Mori \& Christodoulou, 2012) and improve the quality of life of citizens, has recently emerged. The task of smart cities is to drive economic growth and improve the quality of people's lives by enabling the development of local areas and harnessing technology, Smart. Areabased development will transform existing (retrofit and redevelopment) areas, including slums, into better planned areas, thereby improving the city's entire livelihood. New areas (green fields) will be developed around cities to accommodate the growing urban population. Smart Solutions will help cities use technology, information and data to improve infrastructure and services and provide clean water. Smart cities use ICTs to implement their smart strategies and to collect and deliver information to different users, where ICT applications are essential tools in the water management sectors. A number of initiatives are being implemented today to improve water availability, efficiency, accessibility and sustainability through the application of various ICT tools. These tools are one of the most effective ways to promote scarce land and water resources to increase food production, secure human life and work on Achieving the Smart City concept that promotes the deep use of ICTs in the SWM approach to sustainable water resource development and management is well coordinated through the integration of ICT products and tools Lattes and solutions.

\section{1 water resources management in smart cities}

\subsection{Challenges facing the water resources sector}

The provision of clean and reliable water constitutes a key area for the functioning of urban systems. Rapid urbanization, poverty and urban decay, weak political leadership and governance, insufficient and inadequate infrastructure, under investment and pricing issues, are among the key, and mutually re-enforcing factors that impinge upon a city's water management system. These factors are further exacerbated by the impacts of climate change and other environmental stressors, ultimately heightening water management challenges, and constraining the availability and the quality of urban water resources. The interconnected and dynamic nature of urban water management challenges is illustrated in Figure 1. (ITU, 2014)

Figure (1) Influencing factors on urban water management

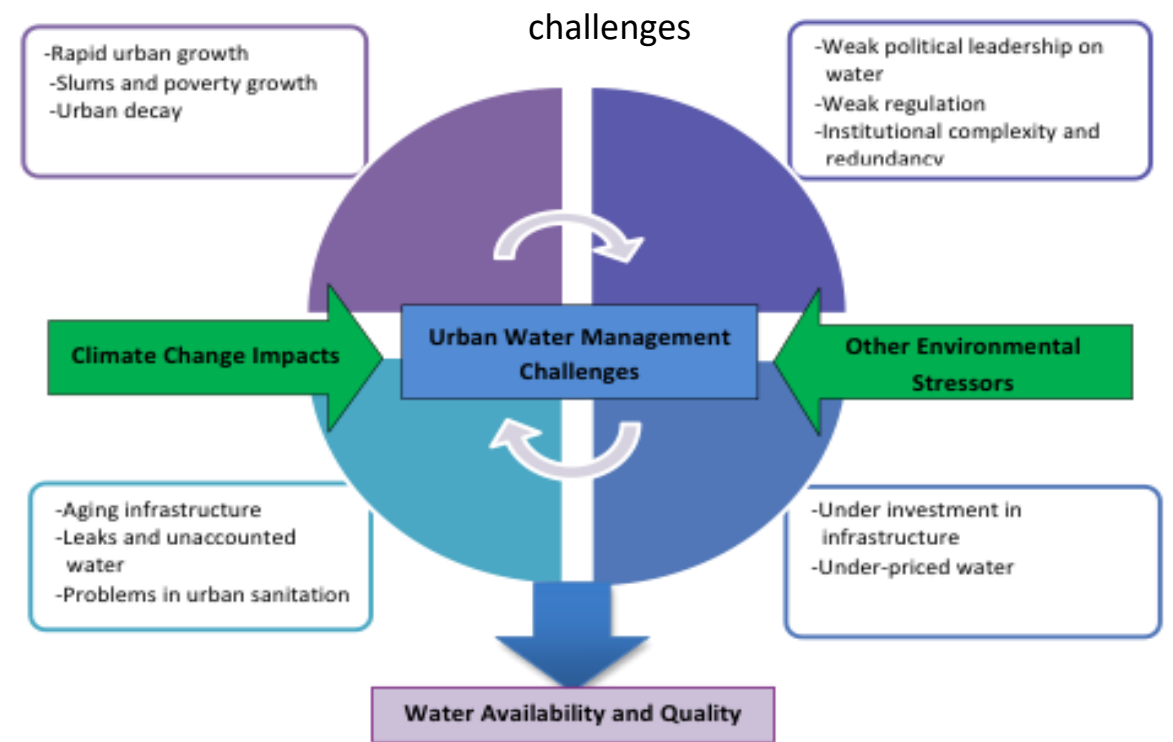

Source: Adapted from Mclntosh (2014) 
The current water shortage in Egypt is 13.5 Billion cubic meter per year (BCM/yr.) and is expected to continuously increase. Currently, this water shortage is compensated by drainage reuse which consequently deteriorates the water quality (Omar \& Moussa, 2016).

The average per capita water consumption in Egypt has deteriorated over the years, declining over the previous periods from 2604 m3 / year 1947 to 769 m3 / year 2006 and is expected to reach $582 \mathrm{~m} 3 /$ year 2025.

Figure (2) Evolution of per capita water availability in Egypt

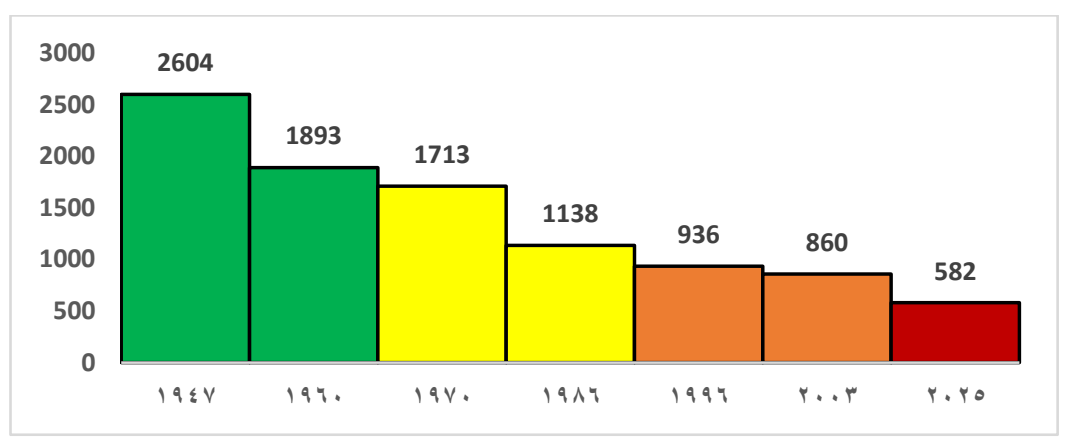

Source: Information and Decision Support center - Council of Ministers - Have Egypt entered the era of water poverty - Information

The challenges facing Egypt's water resources can be summarized into the following five main issues: -

- Population Explosion: - future projections say that the population will grow from its current total of 92 million to 110 million by the year 2025. The rapid population increase multiplies the stress on Egypt's water supply due to more water requirements for domestic consumption and increased use of irrigation water to meet higher food demands.

- Inefficient Irrigation: - Egypt's irrigation network draws almost entirely from the Aswan High Dam, which regulates more than 18,000 miles of canals and sub-canals that push out into the country's farmlands adjacent to the river. This system is highly inefficient, losing as much as 3 billion cubic meters of Nile water per year through evaporation and could be detrimental by not only intensifying water and water stress but also creating unemployment.

- Pollution: - water of Nile is being polluted by municipal and industrial waste, with many recorded incidents of leakage of wastewater, the dumping of dead animal carcasses, and the release of chemical and hazardous industrial waste into the river.

- Regional Upheavals: - A big challenge is tackling the issue of Ethiopia building a dam and hydroelectric plant upstream that may cut into Egypt's share of the Nile. For some time a major concern for Egypt was Ethiopia's construction of the Grand Ethiopian Renaissance Dam (GERD). As the construction of the dam leads to the deduction of about 11 billion $\mathrm{m} 3$ / year, which represents $20 \%$ of the share of Egypt annually in case of filling the dam for six years (Ramadan, Negm , Smanny, \& Helmy, 2013).

Based on the challenges facing the water resources sector, the trend towards smart water resources management, how to develop water management systems and the 
use of information technology in water management was necessary to face these challenges

\subsection{Conceptualizing a smart city}

The concept of the Smart City has grown in importance throughout the world over the last ten years (Cocchia, 2014). The main reasons for the continued increase in the number of people living in urban areas, where the proportion of urban population in $r \cdot l \leqslant$ is $\% 0$ of the total world population, and it is estimated that by $r \cdot \mid V$, the majority of the population in urban areas (World Health Observatory) (United Nations, Department of Economic and Social Affairs, 2015) As well as the challenges of the twenty-first century (OECD, 2010), in building sustainable cities that provide important opportunities for economic development and expand access to basic services, including health care and education, as well as housing, electricity, water and sanitation for heavily urban dwellers, taking into account the impact of human activities on the environment Same time.

The Smart City is a new urban context-based configuration that relies on a set of features associated with improving the quality of citizens' lives. Urban development policies are often addressed by focusing on the non-physical techniques and structures contained in the physical space of the city (Elmquist, Fredberg, \& Ollila, 2009) More recently, the integration of new lifestyles has been driven by more complex innovations, supported by broadband networks and collective intelligence that define the development of the city (Schaffers, et al., 2011). Hence, Smart City seeks to combine ICT with urban planning methods, thereby increasing the sustainability and livability of its citizens, the concept of smart cities is not only limited to technological progress, but also aims to promote social and economic development.

\subsubsection{Smart City Definitions and Core Components}

There are many definitions of the Smart City, with its similarities and differences in what can be called "x-city", where $x$ takes different meanings, often a set of conceptual variables is obtained by replacing "smart" with alternative attributes (O'Grady \& O'Hare, 2012), for example, "Intelligent" or "digital". Smart City is a concept that is not clear and is used in ways that are not always consistent (Neirotti, P., De Marco, A., Cagliano, A. C., Mangano, G., \& Scorrano, F, 2014). There is no single definition to explain a smart city concept, not a one-size-fits-all definition, as seen; the definition of a Smart City is a very broad concept that has technology as a basic aspect, coupled with social and human capital development.

One of the most important definitions that explain the research thought is what was said about " A smart city infuses information into its physical infrastructure to improve conveniences, facilitate mobility, add efficiencies, conserve energy, improve the quality of air and water, identify problems and fix them quickly, recover rapidly from disasters, collect data to make better decisions, deploy resources effectively, and share data to enable collaboration across entities and domains." ( $\mathrm{Nam}$, and T.A. Pardo, 2011), " A city that monitors and integrates conditions of all of its critical infrastructures, including roads, bridges, tunnels, rails, subways, airports, seaports, communications, water, power, even major buildings, can better optimize its resources, plan its preventive maintenance activities, and monitor security aspects while maximizing services to its citizens." (Hall, et al., 2000) The conceptual components (Figure 3) (Doliltte, 2015), of the smart city can be divided into three 
categories: technology, people and institutional investment by directing to sustainable development areas. Here we can say that smart cities are places of futuristic

1. The conceptual components (Figure 3) (Doliltte, 2015), of the smart city can be divided into three categories: technology, people and institutional investment by directing to sustainable development areas. Here we can say that smart cities are places of futuristic thinking in the areas of people, living, economy, governance, environment and mobility

2. places of futuristic thinking in the areas of people, living, economy,

Figure (3) The conceptual components of the smart city

\section{Human Behavior Dechnology}

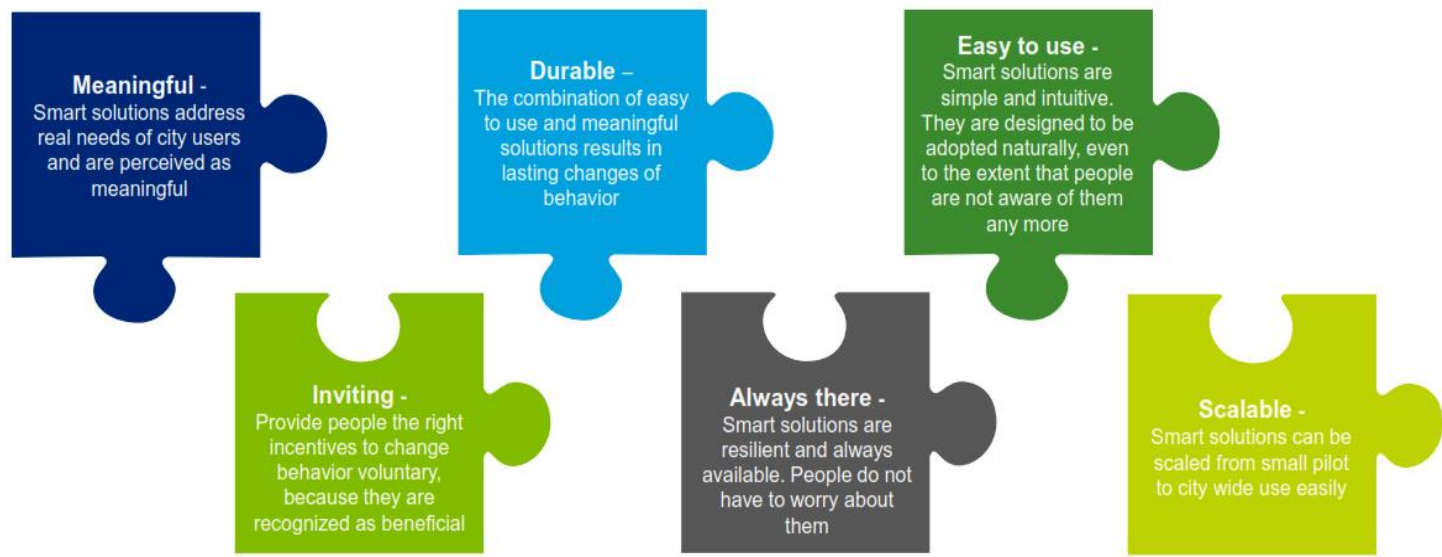

Source: (Doliltte, 2015)

governance, environment and mobility

3. places of futuristic thinking in the areas of people, living, economy, governance, environment and mobility.

\subsubsection{Characteristics of Smart Cities}

Smart cities can be evaluated and developed through six distinct characteristics (Figure 4), as a rating tool for assessing smart cities in the areas of economy, people, governance, mobility, environment and living. Through this model, a city can check its current status and thus identify areas that need further development from In order to meet the necessary conditions for the Smart City (Giffinger, et al., 2007).

Figure (4) Six Characteristics of the Smart City Model
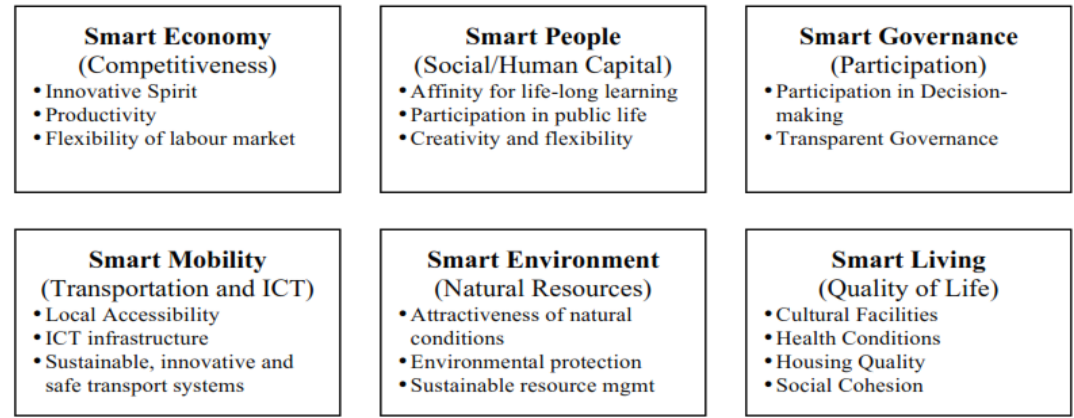

Source: (Giffinger, et al., 2007). 
The smart environment emphasizes the need to manage available resources and sustainable urban planning. By working on the integrated management of water resources, which is interested in research in the light of the integration of new technological innovations that lead to efficiency gains and reduce pollution rates to protect the environment and enhance the natural beauty of the city So smart cities must be water smart.

\subsubsection{Success factors of smart city - Smart water}

Smart water management is a criterion for the success of smart cities. Based on the rich conceptual definitions of the Smart City, there are a number of factors that are essential to the success of smart cities. These factors can be used to achieve the concept of sustainability and include the following factors: governance, technology, governance, Economy, built infrastructure and the natural environment. The concept of smart water management is implicit in the factors necessary for the success of the Smart Cities concept, which is linked to the establishment of an efficient infrastructure in light of the conditions suitable for the natural environment of the city. I find inventions and modern technologies.

The Smart Water City approach integrates urban planning with urban water cycle and benefits them well in society as a whole. This concept includes the integration of rainwater, groundwater, wastewater management and water supply to address societal challenges related to climate change, resource efficiency and energy transfer to reduce environmental degradation. This approach develops complementary strategies for environmental, economic, social and cultural sustainability. Figure 5 illustrates the WSC concept and demonstrates the existence of combined creative opportunities that can be achieved primarily when interfering between the three parts of an urban water cycle (Tim van Hattum, Marina Bergen, Karianne de Bruin, 2016).

Figure (5) Water Smart City: integrating sustainable urban development and urban water management

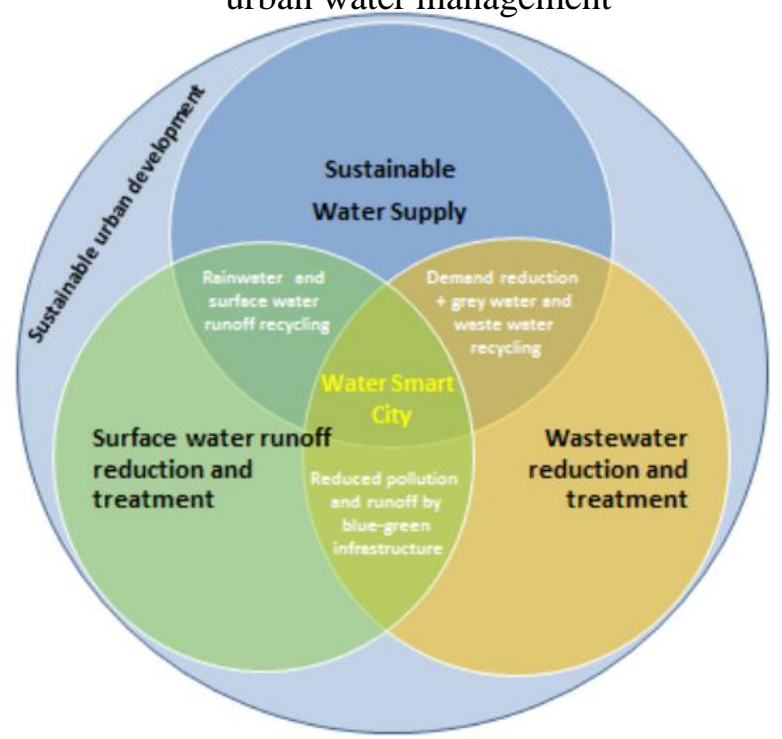

Source : (Tim van Hattum, Marina Bergen, Karianne de Bruin, 2016)

\subsection{Steps towards Water Smart Cities}

In order to get to smart water management in cities we have to take care of a number of steps such as figure 6: 
- Identifying challenges and opportunities: Identify the challenges and opportunities related to the city's water system. This analysis can define the water contract between the city and its citizens and businesses.

- Defining the vision of the WSC: The city's smart city vision must be defined by understanding its own challenges and opportunities for the natural system and the ability to live and the vision must be included among all actors.

- Exploring opportunities for joint creation: To implement the WSC can follow different paths in the plan to make it smarter to visualize the infrastructure projects of the timeline and investigate the possibilities of joint construction by linking the objectives of climate adaptation to planned infrastructure projects

- Joint design solutions: A better analysis of possible measures to determine the best way to reach the aspirations of cities.

- Determining the status of work: Each scenario has its benefits and disadvantages with respect to its performance (including flexibility), costs, value and risks over a given period of time. All these factors must be balanced with each other to determine the optimal business model.

- Implementing and evaluating WSC measures, celebrate and learn from them, and where the process or ambitions need to be modified until the business is done as usual (plan to do - verify - act). Monitoring, correct management and analysis of data is therefore very important. The evidence base is constantly required.

Figure (6) steps towards Water Smart Cities

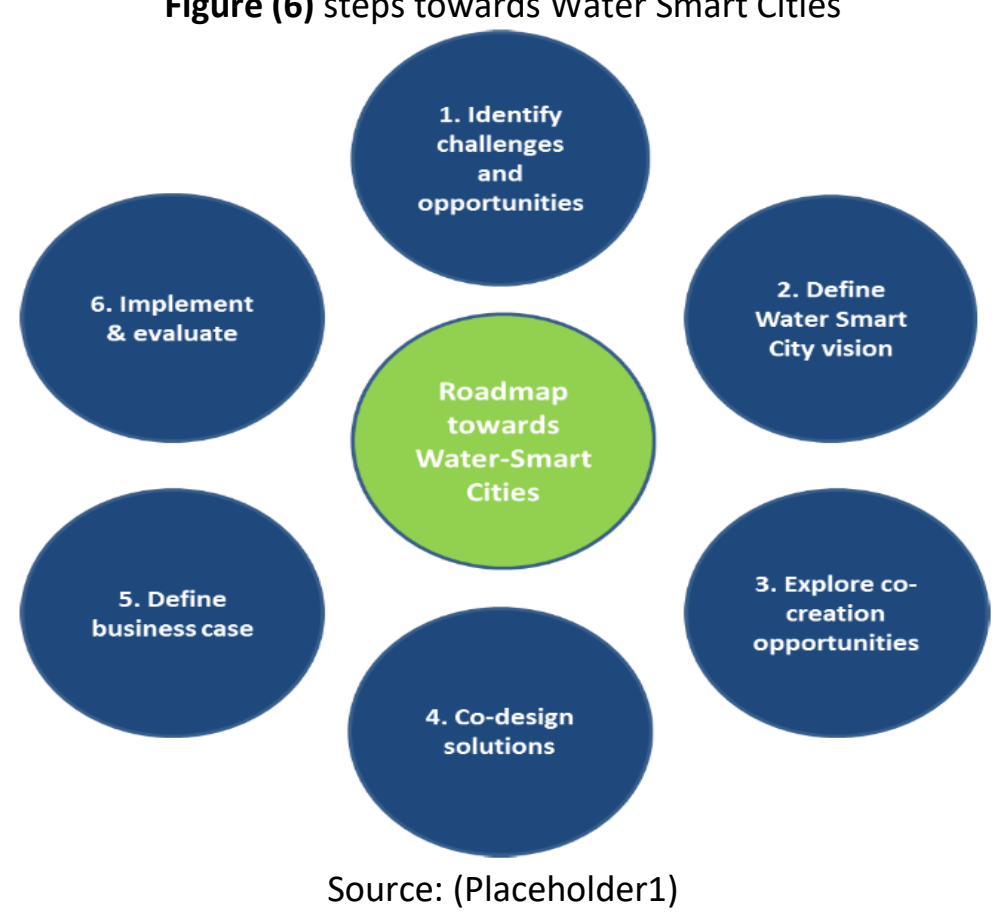

\subsubsection{The relationship between the characteristics of smart cities and ICTs}

Information and communication technology is essential in Smart City to (Mitchell, 2007):

1. Efficient use of infrastructure from a sustainable economic, social and cultural perspective

2. Working on the electronic participation system and involve citizens with the local administration 
3. Supporting the learning experience, adapt, innovate and interact with different variables

The field of Information and communication technology (ICT) is constantly evolving, allowing for strong integration of all the city's intelligent dimensions that point to human intelligence, collective intelligence as well as artificial intelligence to the physical components of the city.

Smart cities are constantly trying to solve water scarcity problems using innovative technologies and better water management. Digital technology is used to help save water, reduce costs and increase water distribution efficiency by interfacing physical pipe networks with data and information networks. The system typically analyzes the flow and pressure data available to identify anomalies (Such as leaks) in real time to better manage water flow.

Figure (7) Characteristics and tools that define the Smart City

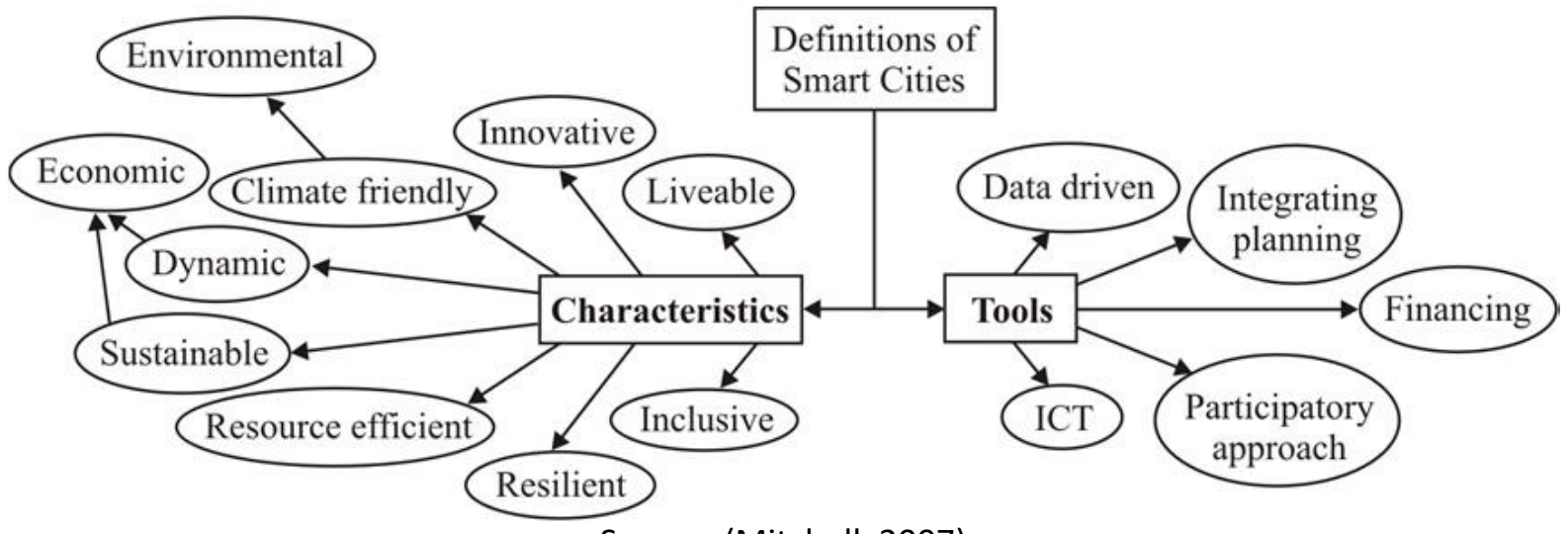

Source: (Mitchell, 2007)

\subsubsection{The relationship between Smart water management and ICTs}

ICT tools enhance the capacity of developing countries to cope with the water-related challenges of climate change, recovery and adaptation (e.g. changes in water supply and demand, availability, governance and governance) (Laspidou, 2014). ICT tools measure how smart work reduces Loss of water resources and ensuring the efficient management of water resources for future decades.

To manage ICT water resources, a methodology is needed to identify strategic priorities and investments that must begin by identifying the different water areas and related activities and defining the associated activities that can be analyzed in relation to ICT solutions figure 8 .

Figure (8) General methodology for development of ICT solutions in the water sector

\section{Water cycle}

1 - Water domains identification

2 - Invariant activities identification

3 - Business processes description \& analysis

4 - Identification of needs in ICT solutions

Source: C. S. Laspidou 2014 


\section{RESULTS AND DISCUSSION}

\section{1 the role of ICT in smart water management in smart cities}

Water management is closely associated with water resource development and environmental protection, and it also entails proper management of the demand for public services and cost effectiveness. Consequently, urban water management must ensure access to water and sanitation infrastructure and services, manage rain, waste and storm water as well as runoff pollution, mitigate against floods, droughts and water borne diseases, while at the same time safeguarding the resource from degradation. (ITU, 2014)

Recognizing the challenges faced by the water sector, stakeholders from academia, corporations and the ICT sector have developed water intelligence tools that use ICTs to alleviate global water issues. The role played by smart water systems in optimizing the efficiency, effectiveness and flexibility of water and wastewater infrastructure assets and their management constitutes a topic of increasing attention, as evidenced in a recent OECD inventory of policies to promote and facilitate the diffusion of these technologies. (OECD, 2013)

ICTs offer valuable opportunities to improve the productivity and efficiency within the water sector, with the aim of contributing to the sustainability of the resource. These technologies allow the continuous monitoring of water resources, providing real-time monitoring and measuring, making improvements in modelling and problem diagnosis, thus enabling proper maintenance and optimization of all aspects of the water network. (ITU, 2014)

The increasing availability of more intelligent, ICT-enabled means to manage and protect the planet's water resources has led to the development of smart water management (SWM). The SWM approach promotes the sustainable consumption of water resources through coordinated water management, by integrating ICT products, solutions and systems, aimed at maximizing the socio-economic welfare of a society without compromising the environment. SWM can be applied to multiple sectors (e.g. industries, agriculture) and urban environments.

In cities, SWM strives to achieve three main goals through the utilization of ICTs, namely:

(a) Coordinated water resource management and distribution, (b) enhanced environmental protection, and (c) sustainable provision of public services and economic efforts.

SWM tools can be categorized in the six main areas listed below. It should be noted that the examples provided are not limited to these areas, but may overlap several others: - (Smart Cities Council, 2013)

- Data acquisition and integration (e.g. sensor networks, smart pipes, smart meters).

- Data dissemination (e.g. radio transmitters, wireless fidelity (Wi-Fi, Internet).

- Modelling and analytics (e.g. geographic information system (GIS), Mike Urban, Aqua cycle, assessing and improving sustainability of urban water resources and systems (AISUWRS), and urban groundwater (UGROW).

- Data processing and storage (e.g. software as a service (SaaS), cloud computing).

- Management and control (e.g. supervisory control and data acquisition (SCADA), optimization tools).

- Visualization and decision support (e.g. web-based communication and information systems tools).

- Transmitting of data and information to cities' technical services and to the end 
users (e.g. Tools for sharing information on water and on services).

The integration of smart water management technologies through realistic, measureable timelines and adequate implementation processes can deliver immediate visible and measureable results in urban water distribution and wastewater management. While challenges still exist, the analysis presented in this Technical Report suggests that the benefits are clear and significant. Through coordinated actions, holistic management, stakeholder involvement, adequate investment, and appropriate technology, SWM can improve both the reliance and sustainability of the water systems and networks. By protecting the safety and reliability of water supplies, increasing the resilience of water infrastructure, reducing flooding and overloads of wastewater systems, decreasing energy consumption, lowering operational costs while increasing customer choice and control, these systems can enable a sustainable water environment for cities to grow and thrive in.

(ITU, 2014)

Recent advances in technology and interconnectedness, once appropriately harnessed, can foster the conditions needed to promote sustainable water resource management in the face of rapid urbanization, water scarcity and climate change. This will enable cities to conduct the following tasks:

- Collect easily real-time data and measurements through sensor networks and lowcost innovative communications and protocols.

- Make better informed decisions through the use of advanced analytics which translate the raw data into actionable intelligence.

- Improve the efficiency, performance and optimization of infrastructure through real-time management systems.

Figure (9) Smart water management tools

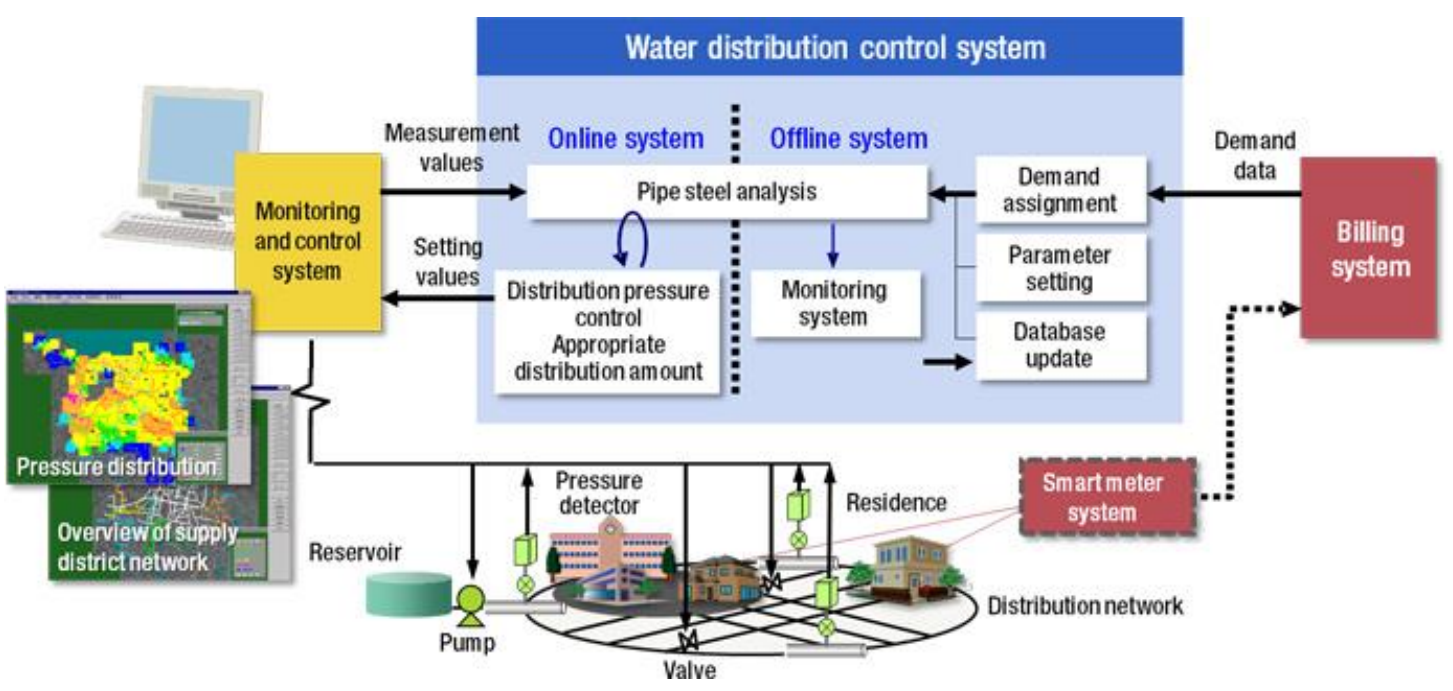

Source: (Kohno, Masuyama, Kato, \& Tobe, 2011)

There are some criteria and indicators that can measure the application of information technology in water resources management, which are divided into:

- Efficient use of water: Expresses the efficiency of the exploitation of water resources.

- Volume of consumption: The amount of water used in different uses is expressed in terms of: - Average per capita water

- Consumption pattern: The type of use of water resources is reflected in the various 
activities (agriculture, industry, daily consumption, etc.)

The effective application of the above criteria and indicators to ensure the effectiveness of IT systems in water resources management is the key element towards achieving smart management of water resources and thus achieving one of the principles and key elements of Smart Cities

A set of standards will be applied to a number of Egyptian cities to assess the extent to which IT systems are applied to water resource management and to identify the gap in access to smart water resource management.

\section{2 water resources management in the cities of Dakahlia governorate}

The main objective of the study is to evaluate the cities of Dakahlia governorate in the field of water resources management and the extent of application of IT systems in order to determine the classification of cities to levels according to the readiness of the application of information technology in water resources management to reach smart management of water resources, Basic in the formation of smart cities, Therefore:

- The study was based on the indicators that were drawn from the previous point and were applied to the Egyptian cities. The case of the study (Dakahlia governorate cities) which was chosen according to it from the governorates of the delta region, which is one of the most Egyptian regions consuming water resources.

- It was also applied to the cities of one governorate of the Egyptian governorates in order to facilitate the data inventory and ensure accuracy

- The indicators that were relied upon in the study are the following:

- Production of potable water (Thousand m3/Day)

- Consumption of potable water (Thousand m3/Day)

- Evolution of the average per capita share of the Consumption of potable water (Litre.day/Person)

- Technological level

There are also a number of indicators that have not been measured at the level of Dakahlia cities so far, such as: -

- The indicator of the number of smart water meters used in the city.

- Lengths of smart pipes used in cities

After calculating the indicators in the next table and preparing a classification for the cities of Dakahlia governorate, the cities were divided into three categories, namely:

- Class A: - The first category includes the highest number of cities in the indices, which are ready to apply the idea of smart management of water resources, includes cities: - El Mansoura - Sherbin - Talkha - Met Ghamr.

- Class B: - The second classification includes cities with the following lowest values of the first classification, which reflect the average values and still need some support in the field of information technology, including cities: - El Senblween - El Manzla - Aga - Belqas - Dekrns - Nabroh.

- Class C:- The third classification includes cities with minimum values of indicators, including cities: - El Gamlya - El Matrya - Bani Ebed - Temi El Amded - Menayt El Nasr - Met Salseel, Which need a set of decisions to raise the level of technology such as: (the establishment of new technological research centers - the development of water management system - raising the efficiency of water use) to access the smart management of water resources which is one of the cornerstones in the formation of smart cities. 
Table (1) Classification of the cities of Dakahlia Governorate according to the application of information technology systems in the management of water resources

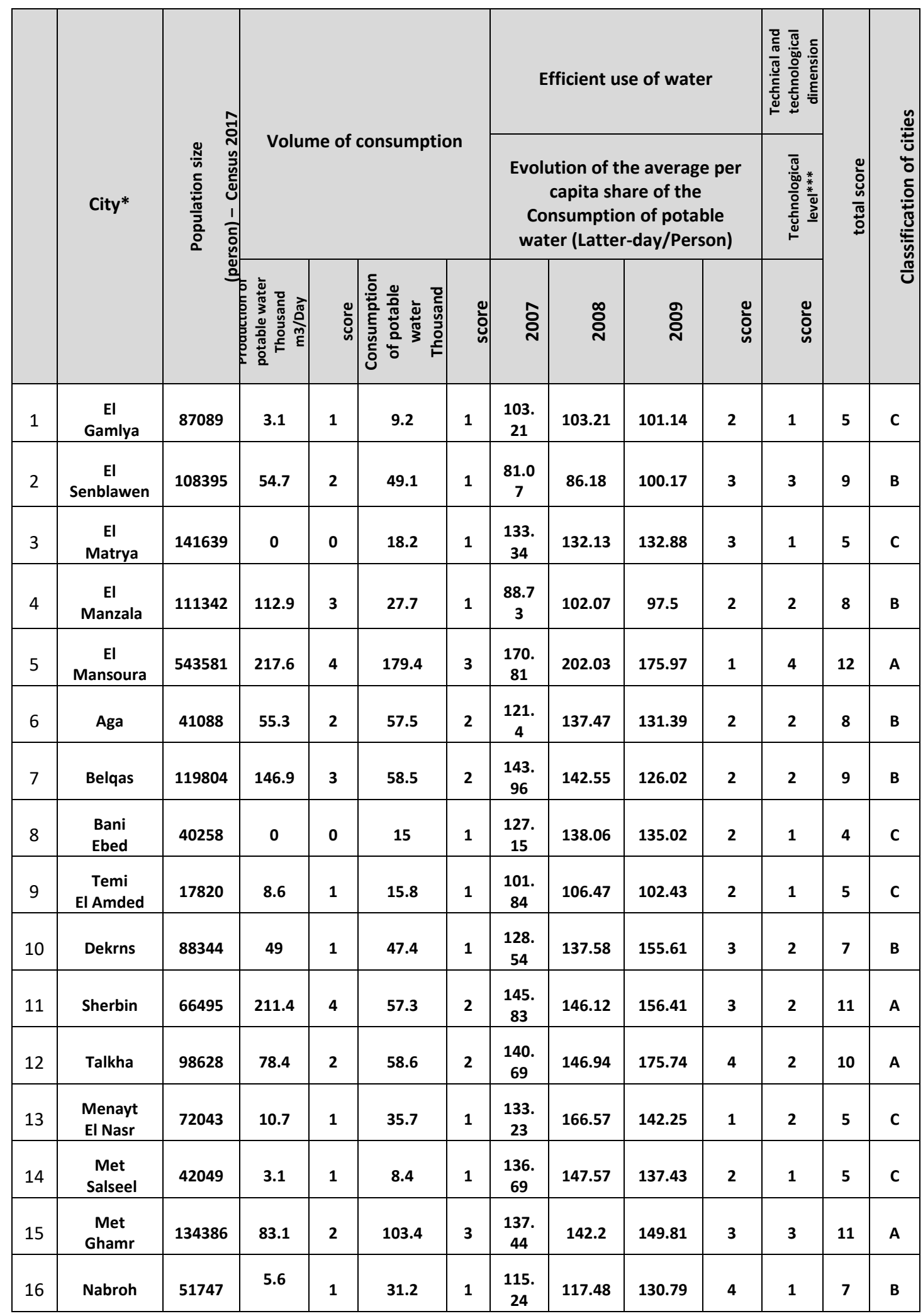

Source: Dakahlia governorate /Researchers 
- Calculation of the indicators was done by the researcher - Data from the centers description report 2010 - Information and Decision Support Center - Council of Ministers

* The indicators were studied on the cities of Dakahlia governorate located in the Delta region

** Technological level: - It was expressed through technical schools and academic libraries in the city

The set of indicators used in the previous table are indicators that can be measured at Dakahlia city level, and it may be possible to check the results when adding a set of indicators that cannot be measured at the moment, such as the use of smart meters and pipes

\subsection{Smart Water Management technologies}

Smart water Management technologies are currently applied to many different areas of water management. When applied to cities, the availability of reliable data to enhance operations can improve decision-making at multiple levels. Many innovative ICT tools have been developed in support of next-generation urban water infrastructure systems, helping to improve performance, increase efficiency, and reduce costs, decrease redundancy, and lower environmental impacts, among others. Some of these smart technologies are explained below: (ITU, 2014)

Smart water management techniques reflect the decisions and processes to be implemented on the cities of Dakahlia governorate with their three categories resulting from the previous practical study to implement their IT systems in order to reach smart management of water resources.

Therefore, the application of these technologies is the only way for the cities of Dakahlia at all levels derived from the previous table to access to smart water management and development of sector performance.

Figure (10) Current implementation of smart water Management technologies and

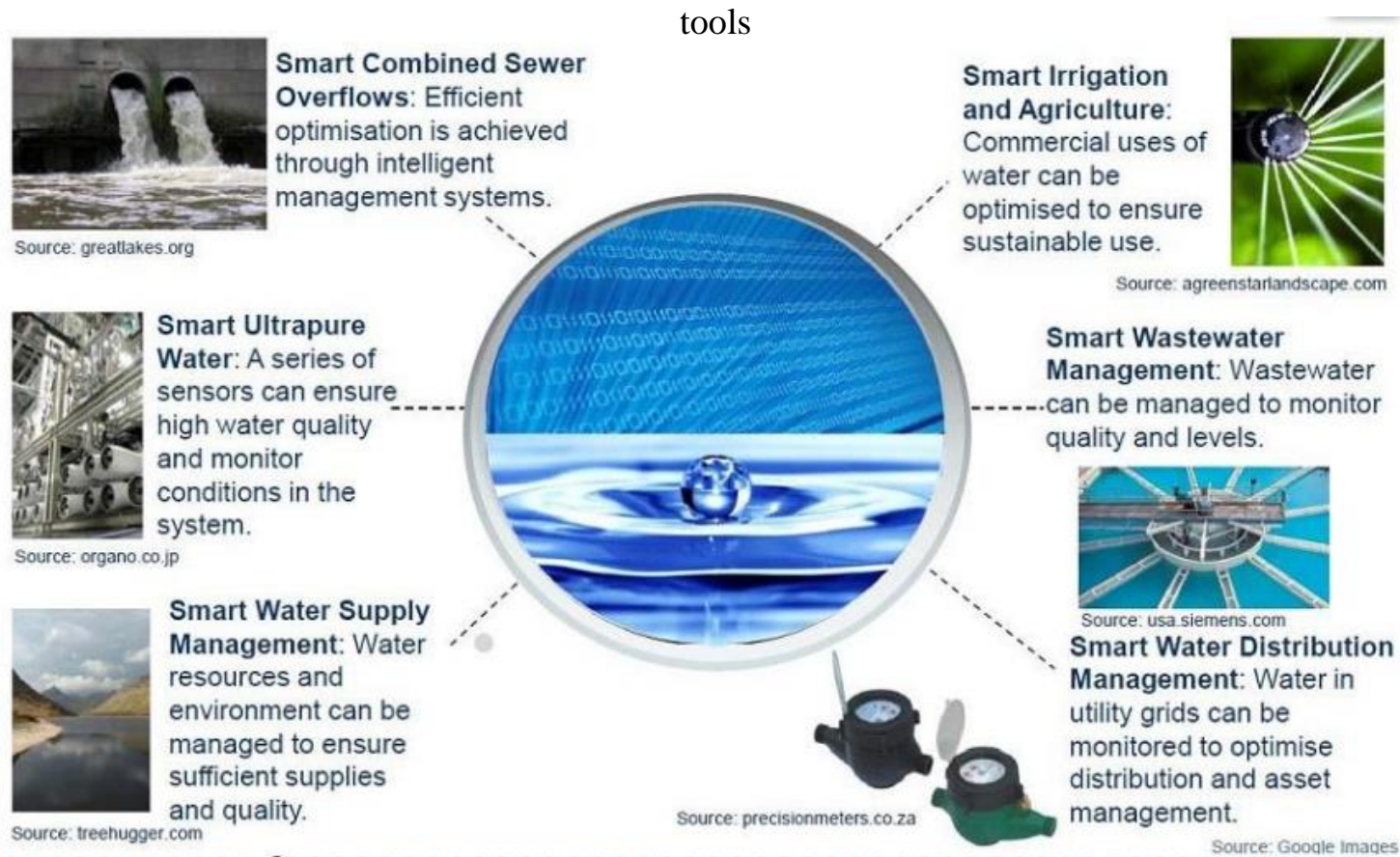

Source: (Hauser, 2012) 


\section{-Smart pipes and sensor networks}

Smart pipes incorporate multifunctional sensors that can sense strain, temperature and pressure anomalies, as well as measure water flow and quality during service, to provide operators with continuous monitoring and inspection features, while assuring safer water supply distribution. Connecting smart pipes with a wireless processor and antenna enables data to be transferred directly to a command center, providing water managers with the tools needed to detect and locate potential leaks in real time. Wireless sensor networks provide the technology for cities to more accurately monitor, and sometimes control, their water supply systems intricately using different parameters. Examples include sensors with the ability to analyze the acoustic signature of a pipe or to monitor soil moisture and detect leaks. (ITU, 2014), Many ICT companies are developing a wide range of sensors specifically designed for water networks, some smart sensors can detect flow rates down to $0,3 \mathrm{~m} 3 / \mathrm{hr}$., ( 5 liters/minute), enabling early-leak detection and thus reducing the risk of pipe break. The system reports pipe flow measurement data with pressure and acoustic measurement combines this information to GIS data and sends automatic alerts to identify the location of possible leaks, thus allowing the prioritization of repair work; Major tasks for smart sensor networks in water quality monitoring include the following:

- Identify and characterize changes in existing or emerging trends in surface water quality over time.

- Gather information to design or assess specific pollution prevention or remediation programs, or to provide information in a timely manner to allow quick response to emergencies, such as spills and sewage leakages.

- Determine whether program goals - such as compliance with pollution regulations or implementation of effective pollution control actions - are being met.

\section{- Smart metering}

The deployment of smart meters within an urban infrastructure enables remote accessibility of consumption data, which improves meter reading and billing, detection of leaks, illegal connections and tamper alerts, and can also enhance the identification of peak demand mainly for energy. Customer and provider relationships are improved through increased communication, utilities can improve their tariffs policies and consumers can be equipped with options like on-line alarms in case of leak or suspicious consumption, or the possibility to change payment methods (e.g. prepaid or postpaid). (Alliance for Water Efficiency, n.d.)

Smart metering also allows water utilities to provide clear water consumption information which can help customers to track and control their water usage, and identifies immediate savings on their bills, thus enabling better distribution network and consumption planning due to its real-time monitoring capabilities. Figure 9 illustrates an example of AMI infrastructure and SWM capabilities.

\section{- Communication modems}

Communication solutions include Bluetooth, Wireless M-Bus communication, global system for mobile communications/general packet radio service (GSM/GPRS), and Ethernet, among others. These solutions allow remote reading of sensors and meters by the direct transfer of real-time or time-stamped data to the central management system of the utility or water authority. The data is then made available online for customer information system (CIS), geographic information systems (GIS), and cloud computing or supervision and data management tools, supporting improved decisionmaking within the system. (ITU, 2014) 


\section{- Geographic information systems (GIS)}

GIS allows visualization and analysis of water resources and human activity data by linking geographic information with descriptive information. This is highly valuable to urban water management in assessing water quality and day-to-day operations on a local and regional scale. Other issues such as flooding can also be mitigated by the use of geographical information, by helping to identify critical areas that are at risk. This is necessary in the development of hazard maps, as well as in the planning of emergency responses. GIS utilization offers more robust analysis, increased efficiency and reduced costs, by integrating information from resource satellites, GIS can cover large river basins which are occupied by some cities. Combined with local rainfall patterns, meteorological and hydrological data, as well as drainage systems, geographical information and interfaces improves urban storm water management by strengthening drainage management and enhancing rainwater reuse, thus helping to reduce the prevalence of urban flooding.

\section{- Supervisory control and data acquisition (SCADA)}

When incorporated into water management systems, supervisory control and data acquisition (SCADA) are computer-controlled systems that contain a large variety of communication systems, allowing monitoring and controlling water treatment and distribution, as well as wastewater collection and treatment. The system allows for supervision through data acquisition and management, and has the ability to process and send commands within the system. The communication system may involve radio, direct wired connections or telemetry.

Globally speaking SCADA systems have contributed to reduce the operating costs of utilities, and have improved water distribution to households, businesses and industry. The monitoring and control functionalities of SCADA systems can help utilities to protect their infrastructure and prevent severe degradation. The implementation of SCADA has been associated to $30 \%$ savings on energy used to manage water systems, $20 \%$ reduction on water loss and $20 \%$ reduction in disruption (Aoun, 2013). Usage of SCADA as part of urban systems can also enhance disaster preparedness through storm water management, as well as support the remote operation and monitoring of major dams and weirs. (Automation World, 2014)

\section{- Models, optimization tools and decision support}

Optimization tools aim to find the best technical, environmental and financial solutions from models. Therefore, "optimization tools and principles have made it possible to develop prescriptive models for optimal management of large scale water resources systems, incorporating ubiquitous uncertainties in the prediction of natural processes and the economic impacts" (Datta and Harikrishna, 2004). The use of optimization tools can play an important role in effective decision-making towards the planning, design and operation of water resource systems. (ITU, 2014)

Models, optimization tools and decision support tools for network management of urban water resources contribute to calculate and forecast consumption, reduce costs through the optimization of operations, plan and evaluate strategies, and also to conduct vulnerability studies to inform strategy design.

\section{- Web-based communication and information system tools}

Information and knowledge management are increasingly recognized as important features for the effectiveness of the water sector (Dondeynaz, Mainardi, CarmonaMoreno, Italy, \& Leone, 2009). A key problem faced within the sector is the existence of a large body of complex, unstructured and fragmented data. Web-based interfaces 
and online platforms provide a solution to enable the effective management, display, and retrieval of relevant information required by water managers/operators, urban planners, governments and the public. (ITU, 2014)

Web-based servers offer access to integrated information from heterogeneous data sources, as well as innovative tools for the analysis and assessment of issues such as climate change, water scarcity, human health, sanitation and urbanization, all key factors to consider as part of urban water management. The integration of such webbased communication tools using open communication standards allows a range of stakeholders to connect to the system, and use available resources.

At the same time, communication and information systems can enable both the general public and administrators to access relevant information, fostering transparency and visibility of current water related activities by the specialized users (e.g. water managers, municipalities, governments), facilitating trust-building and public/stakeholder involvement. An intuitive and user friendly interface fosters data accessibility and dissemination, especially for the public.

\section{Conclusion}

The water sector is a major challenge for the 21st century. Climate change, coupled with increased population pressure, creates a lot of pressure on limited water resources that must be carefully managed. The rapid development of ICT solutions today allows for a new area of transition from data scarcity to flow Data-rich world "a natural and built environment that allows improved water management and promotes the concept of smart cities at the global level, which is concerned with the development of a vision based on a process that allows the integration of activities with information and communication technology solutions $T$ in the light of the guidelines and standards must be defined jointly by the different actors in the sectors of water development and other sectors.

Smart Water is a new concept that aims to maximize the benefits of ICT-enabled services in the water sector. ICTs can help the water sector reduce leakage and consumption by deploying appropriate technology or using digital technologies to raise awareness and encourage change Consumer's behavior.

In the practical study, some indicators of the application of information technology systems in the management of water resources in the cities of Dakahlia governorate were calculated that reflect the use of technology in water management, water consumption rates, and the availability of technological centers in cities that can be used as teaching centers to qualify workers and employees on management. Cities were divided into three levels according to the application of these regulations.

Therefore, a series of smart water resources management techniques have been proposed to achieve the principles of smart cities such as the use of smart meters and pipes, the application of GIS in water management, and the formation of an integrated electronic system for the management of the sector in terms of rapid identification of problems and accurate decisions immediately.

\section{References}

Alliance for Water Efficiency. (n.d.). Metering and Submetering. Retrieved from https://www.allianceforwaterefficiency.org/resources/metering\#

Aoun, C. (2013). The Smart City Cornerstone: Urban Efficiency. Schneider Electric.

Cocchia, A. (2014). Smart and Digital City: A Systematic Literature Review. In R. P. Dameri, \& C. Rosenthal-Sabroux, Smart City: How to Create Public and Economic Value with High Technology in Urban Space (pp. 13-43). Switzerland: Springer. 
Doliltte. (2015). Smart Cities: How rapid advances in technology are reshaping our economy and society. The Netherlands: Deloitte. Retrieved from www.deloitte.nl/govlab

Dondeynaz, C., Mainardi, P., Carmona-Moreno, C., Italy, \& Leone, A. (2009). A web based communication and information system tool for water management in developing countries. In Water, sanitation and hygiene-Sustainable development and multisectoral approaches: Proceedings of the 34th WEDC International Conference. 1, pp. 169-173. Addis Ababa, Ethiopia: Loughborough University.

Elmquist, M., Fredberg, T., \& Ollila, S. (2009). Exploring the Field of Open Innovation. European Journal of Innovation Management, 12(3), 326-345.

Giffinger, R., Fertner, C., Kramar, H., Kalasek, R., Pichler-Milanovic, N., \& Meijers, E. (2007). Smart Cities: Ranking of European Medium-Sized Cities. Austria: Vienna University of Technology.

Hall, R. E., Bowerman , B., Braverman , J., Taylor , J., Todosow , H., \& Wimmersperg , U. (2000). The vision of a smart city. In Proceedings of the 2nd International Life Extension Technology Workshop. Paris, France.

Hauser, A. (2012). An Architectural Framework for Smart Water Networks.

ITU. (2014). ITU-T Focus Group on Smart Sustainable Cities: Smart water management in cities.

Kohno, M., Masuyama, Y., Kato, N., \& Tobe, A. (2011). Hitachi’s Smart City Solutions for New Era of Urban Development. Hitachi Review, 60(2), 79-88.

Laspidou, C. S. (2014). ICT and stakeholder participation for improved urban water management in the cities of the future. Water Utility Journal, 8, 79-85.

Mitchell, W. (2007). Intelligent cities [online article]. UOC Papers(5).

Mori, K., \& Christodoulou, A. (2012). Review of Sustainability Indices and Indicators: Towards a New City Sustainability Index (CSI). Environmental Impact Assessment Review, 32(1), 94-106.

Nam, and T.A. Pardo. (2011). Conceptualizing Smart City with Dimensions of Technology, People, and Institutions. In Proceedings of the 12th Annual International Digital Government Research Conference: Digital Government Innovation in Challenging Times, (pp. 282-291). Retrieved from https://doi.org/10.1145/2037556.2037602

Neirotti, P., De Marco, A., Cagliano, A. C., Mangano, G., \& Scorrano, F. (2014). Current Trends in Smart City Initiatives: Some Stylised Facts. Cities, 38, 25-36.

OECD. (2010). Green Cities Programme.

OECD. (2013). Policies to Support Smart Water Systems: Lessons from Countries Experience. Paris: Working Party of Biodiversity, Water and Ecosystems, OECD Environment Policy Committee.

O'Grady, M., \& O'Hare, G. (2012). How Smart Is Your City? Science, 335(6076), 1581-1582. doi:DOI: $10.1126 /$ science. 1217637

Omar, M. M., \& Moussa, A. M. (2016). Water management in Egypt for facing the future challenges. Journal of Advanced Research, 7(3), 403-412.

Ramadan, E. M., Negm , A. M., Smanny, M., \& Helmy, A. (2013). Environmental Impacts Of Great Ethiopian Renaissance Dam On The Egyptian Water Resources Management And Security. In The 23rd. International Conference On: Environmental Protection is a Must. Alexandria .

Schaffers, H., Komninos, N., Pallot, M., Trousse, B., Nilsson, M. and Oliveira, A. (2011). Smart cities and the future internet: towards cooperation frameworks for open innovation.

Schaffers, H., Komninos, N., Pallot, M., Trousse, B., Nilsson, M., \& Oliveira, A. (2011). Smart Cities and the Future Internet: Towards Cooperation Frameworks for Open Innovation. In J. Domingue, A. Galis, A. Gavras, T. Zahariadis, D. Lambert, F. Cleary, . . . M. Nilsson (Eds.), The Future Internet (Vol. 6656, pp. 431-446). Berlin: Springer.

Smart Cities Council. (2013). Smart Cities Readiness Guide: The Planning Manual For Building Tomorrow's Cities Today. Retrieved from https://www.corviale.com/wpcontent/uploads/2013/12/guida-per-le-smart-city.pdf

Tim van Hattum, Marina Bergen, Karianne de Bruin. (2016). Towards Water Smart Cities Climate adaptation is a huge opportunity to improve the quality of life in cities. (Wageningen 
Environmental Research rapport; No. 2787). Wageningen University \& Research. Retrieved from https://edepot.wur.nl/407327

United Nations. (2008). World Urbanization Prospects: The 2007 Revision Population Database. New York: United Nations.

United Nations, Department of Economic and Social Affairs. (2015). World Population Prospects: The 2015 Revision, Key Findings and Advance Tables. New York: United Nations. 